\title{
The meaningfulness and meaning of schematic faces*
}

\author{
STUART J. McKELVIE† \\ Bishop's University, Lennoxville, Quebec, Canada
}

\begin{abstract}
A pool of 128 schematic faces was generated by varying brow, mouth, nose, eye height, and eye shape. Ratings of meaningfulness (how easy it was to find an adjective describing the face) and meaning (the adjective given to the face) were mainly a function of brow and mouth. When brow and mouth were horizontal, faces were least meaningful and neutral in expression; if either brow or mouth moved from the horizontal, faces increased in meaningfulness, meaning being dependent on the moving feature; when both brow and mouth moved from the horizontal, faces were most meaningful, and their expression was a function of the combination of brow and mouth.
\end{abstract}

Although our perception of facial expression is undoubtedly linked to variations among the component features of faces, extensive research over the last 50 years has failed to reveal the exact nature of this relationship. To some extent, inconsistency among research findings can be attributed to methodological differences (Davitz, 1964). For example, the face has been represented by spontaneous photographs (Dunlap, 1927; Hanawalt, 1944; Landis, 1929; Munn, 1940), posed photographs (Feleky, 1914; Frijda, 1953; Frois-Wittman, 1930; Hanawalt, 1944; Kanner, 1931; Plutchik, 1962; Ruckmick, 1921; Samuels, 1939; Secord \& Muthard, 1955), detailed drawings (Buzby, 1924; Frois-Wittman, 1930; Langfeld, 1918), and schematic outline drawings (Bradshaw, 1969; Brunswik \& Reiter, 1937; Harrison, 1964; Rohracher, 1951; Samuels, 1939).

However, after a careful review of this research, Ekman, Friesen, and Ellsworth (1972) conclude that its most important shortcoming is its oversimplified view of how facial components might be related to expression. In particular, two common assumptions seem to be unwarranted, namely, that different facial areas contribute independently to the expression and that there is only one movement in each facial area for each expression.

Schematic faces provide a convenient stimulus by which to evaluate Ekman et al's suggestion, since E has strict control over how they are constructed. Three of the schematic face studies (Bradshaw, 1969; Brunswik \& Reiter, 1937; Samuels, 1939) generated their stimuli by varying the placement of the nose, eyes, and mouth. One of these studies (Bradshaw, 1969) did indicate some interactive effects among features; for example, high eyes and a short nose implied "generosity" when combined with a wide mouth and "youth" when combined with a narrow mouth.

However, although such variations produce faces that are more meaningful than simple patterns, they do not

*This report is based on a rating study of schematic faces carried out while the author was a graduate student at McGill University.

$\dagger$ Requests for reprints should be sent to Stuart J. McKelvie, Department of Psychology, Bishop's University, Lennoxville, Quebec, Canada. produce faces with clearly identifiable expressions. Most of the expressive meaning in a schematic face appears to be contained in changes of the angle of the brows and mouth (Harrison, 1964; Rohracher, 1951). Harrison's study isolated four major categories of expression-happy, sad, angry, and bored (vacant). Notably, Ekman et al conclude that a somewhat similar list can be identified on the basis of studies using photographs and drawings-happy, sad, angry, vacant (interest), surprised, disgusted, and afraid.

Ekman et al's proposal that facial features interact in different ways to produce expressions appears to be upheld when brow and mouth are included as features in schematic faces: Harrison reports that while medially upturned brows imply sadness when combined with a straight or downturned mouth, they indicate happiness in combination with an upturned mouth. He concludes, like Ekman et al, that different facial areas are not independent, but operate together in a variety of ways. One study using schematic faces appears to be at odds with this conclusion: Tversky and Krantz (1969) found that faces could be analyzed into different features that combined additively to give the overall impression. However, according to Harrison's findings, two of the three features involved in the construction of their faces (head shape and eye shading) contribute very little towards any identifiable expression. Interactions among the components of these faces would be expected to be minimal.

The first aim of the present study is to replicate Harrison's finding that brow and mouth interact to determine the meaning of a schematic face. This would provide further support for Ekman et al's conclusion that expression is not just dependent on one feature operating independently of others.

Most of the research on the relationship between component features and facial expression has focused on identifying what expression or meaning is signified by different features. This emphasis simplifies the relationship by ignoring the possibility that some faces are more meaningful than others. If there are variations in the ease with which different faces can be given identifiable expressions, this should be included in any specification of the relationship between expression and 


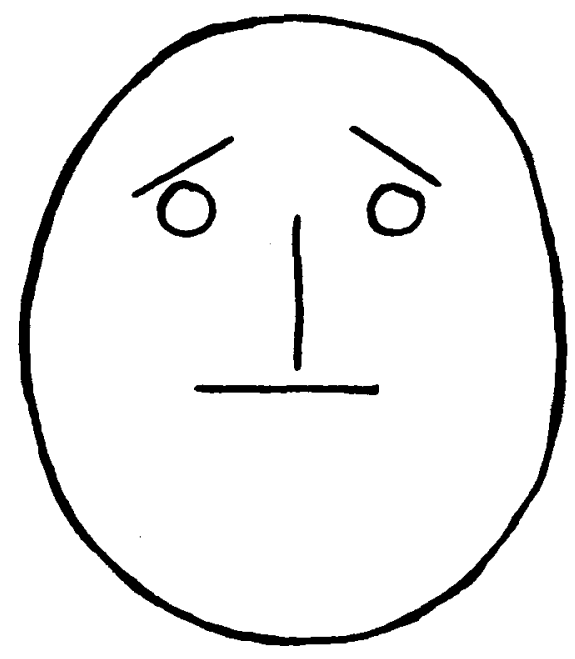

Fig. 1. A typical schematic face.

facial features. Thus, the second aim of this study is to investigate how the meaningfulness of schematic faces is related to their component features. It would be expected that if brow and mouth jointly determine the meaning of a face, then they would also be the major determinants of its meaningfulness.

\section{METHOD}

\section{Stimuli}

A pool of 128 schematic faces was generated by varying brow (B), mouth (M), nose (N), eye height (EH), and eye shape (ES) as follows: (a) The four brows were horizontal and distant from the eyes, horizontal and close to the eyes, medially downturned and close to the eyes, medially upturned and close to the eyes; (b) the four mouths were horizontal and wide, horizontal and narrow, upturned and wide, downturned and wide; (c) the two noses were long and short; (d) the two eye heights were high in the head, in the middle of the head; (e) the two eye shapes were round and oval. All features were placed in a standard oval outline $2 \frac{1}{2} \mathrm{in}$. in height and $2 \mathrm{in}$. in breadth. The distances between the bottom of the nose and center of the mouth and between the top of the nose and the eyes were constant for all faces. A typical configuration is presented in Fig. 1.

\section{Subjects}

The Ss were 64 paid volunteers from the McGill University student population.

\section{Design}

The Ss were placed randomly into eight groups, with eight Ss in each group. Each group rated one of eight matched sets of 16 different faces, so that each member of the pool was rated eight times. The 16 faces in each set represented one example of each of the $16 \mathrm{brow} / \mathrm{mouth}$ combinations and two examples of each of the 8 nose/eye combinations.

\section{Procedure}

The Ss were given a booklet containing 16 pages, with one face on each page, and asked to proceed from Page 1 to Page 16, in that order. Four different random orders were used. For each face, Ss were required to make two types of judgment: (a) meaningfulness-how easy it was to find an adjective to describe the face, and (b) meaning-how appropriate each of 46 adjectives were for describing the face.

All ratings were made by marking $70-\mathrm{mm}$ rating lines at the point corresponding to $S$ 's judgment. The middle of the line served as a neutral point. For meaningfulness judgments, the further to the left $S$ marked, the more meaningful (easy to label) he thought the face was, and the further to the right, the more meaningless (hard to label) he thought the face was. With the adjective judgments, the further to the left that $S$ marked, the more appropriate he considered that adjective to be for that face, the further to the right, the more inappropriate the adjective. "Inappropriate" was defined as meaning that the adjective in question was the opposite of the adjective that would be appropriate.

Some of the 46 adjectives were selected from the four major categories of expression isolated by Harrison (1964): happy, sad, angry, bored (vacant). The rest were added on the basis of a short preliminary study in which graduate students freely described how a broad selection of the faces looked. A nother major category of expression (scheming) was added on the basis of these data. Table 1 shows the adjectives representing each category of expression.

\section{Scoring Procedures}

Judgments were scored by measuring the distance of the marks in millimeters from the left-hand side of the line. Thus, low scores on meaningfulness and appropriateness indicated that the face was meaningful and the adjective in question appropriate; similarly, high scores indicated that the face tended to be meaningless and the adjective in question inappropriate. For each face, measures of meaningfulness and appropriateness for each adjective were found by averaging across the eight judgments of each type.

Each face was then assigned points in each of the expression categories as follows: First of all, adjectives were given 3,2, 1, or 0 appropriateness points on each face, according to whether their appropriateness ratings fell below the $10-\mathrm{mm}$ mark, between the $10-$ and $20-\mathrm{mm}$ marks, between the $20-$ and $30-\mathrm{mm}$ marks, or above the $30-\mathrm{mm}$ mark on the line, respectively. Faces were then assigned points in each expression category by adding together the points received on adjectives in the categories. For example, the face illustrated in Fig. 1 obtained appropriateness ratings of less than $30 \mathrm{~mm}$ on seven adjectives from the sad category and one adjective from the vacant category. Two of the

Table 1

Adjectives Representing Categories of Expression Used in Rating of Faces

\begin{tabular}{lllll}
\hline Happy & \multicolumn{1}{c}{ Sad } & Angry & Scheming \\
\hline Content & Apprehensive & Angry & Cruel \\
Friendly & Ashamed & Annoyed & Mean & Aloof \\
Happy & Dejected & Disapproving & Nasty & Bored \\
Lively & Disappointed & Domineering & Scheming & Insipid \\
Jolly & Perplexed & Furious & Sly & Submissive \\
Pleasant & Sad & Glowering & & Timid \\
& Worried & Stern & Vacant \\
\hline
\end{tabular}


Table 2

Mean Meaningfulness Ratings and Mean Number of Points Obtained by Each Feature Variation in Each Expression Category

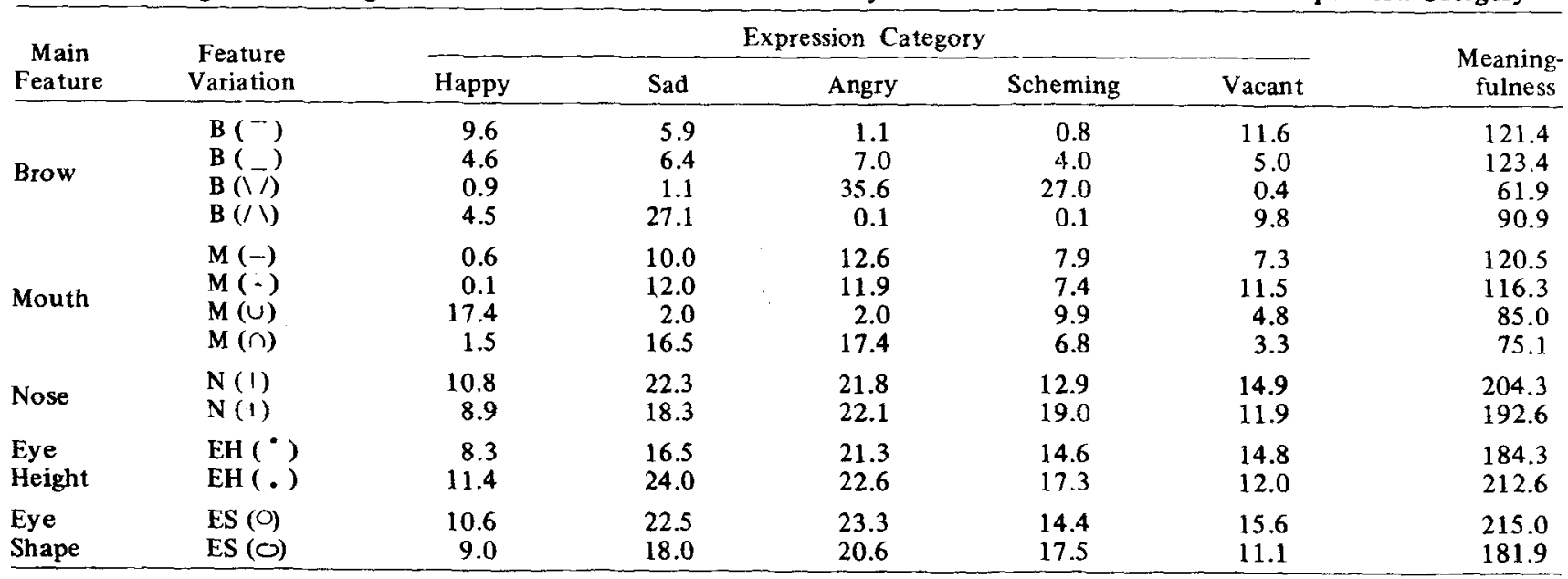

sad adjectives had scores between 10 and $20 \mathrm{~mm}$; the other six adjectives had scores of between 20 and $30 \mathrm{~mm}$. Thus, the face was assigned 9 points $(2+2+1+1+1+1+1)$ in the sad category and 1 point in the vacant category.

\section{RESULTS}

\section{Facial Features and Their Meaning}

To assess the exact meaning implied by each of the feature variations, the number of points obtained in each expression category by faces containing each variation was counted. The average counts over the eight matched groups for each component feature are displayed in Table 2.

Two-way analyses of variance (main feature, expression category), with repeated measures on both factors (all eight groups were exposed to all features and all adjectives), revealed significant interactions between brow and expression category $[F(12,84)=6.84$, $p<.01]$ and mouth and expression category $[F(12,84)$ $=5.14, \mathrm{p}<.01]$. Interactions for nose, eye height, and eye shape were not significant. Tests of the simple main effects of expression category at each brow and mouth variation (Winer, 1962) showed significant differences in meaning at all component features ( $\mathrm{ps}<.01$ ), with one exception (horizontal brows close to the eyes). Finally, Tukey (a) tests (Winer, 1962) on the pairs of means to each significant simple main effect produced the orderings shown in Table 3. (It should be noted that, since the Tukey (a) test is rather conservative, these comparisons did not always reach significance, despite the significant simple main effect.)

It is clear that horizontal brows and mouths contribute little to meaning; horizontal mouths tend not to be seen as happy, but otherwise these components show no differential pattern over the expression categories. However, when brow and mouth move from the horizontal, clear differences in meaning emerge: medially downturned brows indicate anger or schemingness; medially upturned brows are seen as sad; an upturned mouth denotes happiness; and a downturned mouth is seen as angry or sad.

Since both brow and mouth were related to the expression categories, but not uniquely, they were next considered in combination. The number of points obtained by each of the 16 brow/mouth combinations in each expression category was counted. The number of points obtained, averaged over the eight matched groups, is shown in Table 4.

An analysis of variance of these data showed a significant interaction between brow/mouth combination and expression category $[F(60,420)=5.59$, $p<.01]$. With the exception of Combinations 2 and 3 , all simple main effects were significant $(p s<.01)$. Tukey (a) comparisons were carried out at each significant simple main effect, producing the orderings in Table 5 .

Once again, horizontal brows and mouth have no special meaning: in combination, as in isolation, they are not related to any category of expression (Combinations 1-4); when they are combined with other features, they contribute little, the combination being characterlzed by the moving feature (Combinations $5,9,10,13,14$ ). It is notable, however, that only one combination involving a mouth and horizontal brow (No.5) attained

Table 3

Ordering of Expression Categories on Each Feature Variation

\begin{tabular}{|c|c|c|}
\hline \multicolumn{2}{|c|}{ Feature } & \multirow[b]{2}{*}{$\begin{array}{c}\text { Ordering } \\
\text { (Happy, Sad, Angry, Scheming, Vacant) } \\
\end{array}$} \\
\hline Main & $\begin{array}{c}\text { Varia- } \\
\text { tion }\end{array}$ & \\
\hline Brow & $\begin{array}{l}\mathrm{B}(-) \\
\mathrm{B}(-) \\
\mathrm{B}(-/) \\
\mathrm{B}(/ 1)\end{array}$ & $\begin{array}{l}\text { All Categories Equal } \\
\text { All Categories Equal } \\
\text { (Angry, Scheming) }>* * \text { (Happy, Sad, Vacant) } \\
\text { Sad }>* * \text { (Happy, Angry, Scheming, Vacant) }\end{array}$ \\
\hline Mouth & $\begin{array}{l}M(-) \\
M(-) \\
M(u) \\
M(\cap)\end{array}$ & $\begin{array}{l}\text { Happy }<* \text { Angry } \\
\text { Happy }<* \text { (Sad, Angry, Vacant) } \\
\text { Happy }>^{*} \text { (Sad, Angry, Vacant) } \\
\text { (Angry. Sad) }>* * \text { (Happy, Scheming, Vacant) }\end{array}$ \\
\hline
\end{tabular}


Table 4

Mean Meaningfulness Ratings and Mean Number of Points Obtained by Each Brow/Mouth Combination in Each Expression Category

\begin{tabular}{|c|c|c|c|c|c|c|c|}
\hline \multirow{2}{*}{\multicolumn{2}{|c|}{$\begin{array}{l}\text { Brow/Mouth } \\
\text { Combination }\end{array}$}} & \multicolumn{5}{|c|}{ Expression Category } & \multirow{2}{*}{$\begin{array}{c}\text { Meaning- } \\
\text { fulness } \\
\end{array}$} \\
\hline & & Happy & Sad & Angry & Scheming & Vacant & \\
\hline 1 & $\mathrm{~B}(-) \mathrm{M}(-)$ & 0.3 & 1.4 & 0 & 0.1 & 2.6 & 37.5 \\
\hline 2 & $B(-) M(-)$ & 0.3 & 0.4 & 2.3 & 1.1 & 2.3 & 36.3 \\
\hline 3 & $\mathrm{~B}(-) \mathrm{M}(-)$ & 0 & 0.9 & 0.1 & 0 & 4.8 & 35.9 \\
\hline 4 & $\mathrm{~B}\left({ }_{-}\right) \mathrm{M}(-)$ & 0 & 1.3 & 1.1 & 0.8 & 2.5 & 37.4 \\
\hline 5 & $B(-) M(\omega)$ & 11.3 & 0.1 & 0.3 & 0.4 & 1.0 & 18.4 \\
\hline 6 & $B(-) M(U)$ & 4.4 & 0.1 & 0.1 & 1.5 & 0.1 & 29.3 \\
\hline 7 & $B(-) M(\neg)$ & 0 & 3.5 & 0.8 & 0.3 & 1.4 & 29.6 \\
\hline 8 & $B(-1) M(\cap)$ & 0 & 4.6 & 3.5 & 0.6 & 0.1 & 18.6 \\
\hline 9 & $\mathrm{~B}(1 /) \mathrm{M}(-)$ & 0 & 0.3 & 10.4 & 6.6 & 0.1 & 20.4 \\
\hline 10 & $\mathrm{~B}(1) \mathrm{M}(-)$ & 0 & 0.6 & 10.6 & 6.6 & 0.1 & 18.6 \\
\hline 11 & $B(1 /) M(U)$ & 0.9 & 0 & 1.6 & 7.9 & 0 & 11.9 \\
\hline 12 & $B(i n M(\cap)$ & 0 & 0.3 & 13.0 & 5.9 & 0.1 & 11.0 \\
\hline 13 & $\mathrm{~B}(/) \mathrm{M}(-)$ & 0.3 & 8.0 & 0 & 0 & 2.4 & 25.1 \\
\hline 14 & $B(1) M i-)$ & 0 & 9.3 & 0 & 0 & 4.0 & 24.5 \\
\hline 15 & $B(\sim) M(C)$ & 3.4 & 1.1 & 0 & 0.1 & 1.8 & 25.5 \\
\hline 16 & $B(/ \cup M(\cap)$ & 0 & 9.7 & 0.1 & 0 & 1.6 & 11.9 \\
\hline
\end{tabular}

significance. Although upturned and downturned mouths were shown to be related to happiness and sadness or anger when considered in isolation, the effect only shows up once in combination with a horizontal brow. This remark does not apply to moving brows, which are consistently seen as angry, scheming, or sad in combination with a horizontal mouth.

When moving features combine, they can reinforce each other (Combinations 12 and 16 are angry and sad, respectively, because brow and mouth can be angry or sad in isolation), produce a new expression (Combination 11, involving angry brows and a happy mouth is seen as scheming), or produce a neutral expression (Combination 15, which is composed of sad brows and a happy mouth, is not significantly related to any expression category).

Table 5

Ordering of Expression Categories on

Each Brow/Mouth Combination

\begin{tabular}{|c|c|c|}
\hline \multicolumn{2}{|r|}{$\begin{array}{l}\text { Brow/Mouth } \\
\text { Combination }\end{array}$} & \multirow{2}{*}{$\begin{array}{c}\text { Ordering } \\
\text { (Happy, Sad, Angry, Scheming, Vacant) }\end{array}$} \\
\hline 1 & $\mathrm{~B}(-) \mathrm{M}(-)$ & \\
\hline 2 & $\mathrm{~B}(-) \mathrm{M}(-)$ & All Ca tegories Equal \\
\hline 3 & $\mathrm{~B}(-) \mathrm{M}(-)$ & All Categories Equal \\
\hline 4 & $\mathrm{~B}\left({ }_{-}\right) \mathrm{M}\left(\mathbf{C}_{-}\right)$ & All Categories Equal \\
\hline 5 & $\mathrm{~B}(-) \mathrm{M}(U)$ & Happy $>* *$ (Sad, Angry, Scheming, Vacant) \\
\hline 6 & $\mathrm{~B}(\ldots) \mathrm{M}(U)$ & All Categories Equal \\
\hline 7 & $\mathbf{B}(-) \mathbf{M}(\cap)$ & All Categories Equal \\
\hline 8 & $\mathbf{B}(-) \mathbf{M}\left(r_{i}\right)$ & All Categories Equal \\
\hline 9 & $\mathrm{~B}(1) \mathrm{M}(-)$ & (Angry, Scheming) $>$ (Happy, Sad, Vacant $)$ \\
\hline 10 & $\mathrm{~B}(1 /) \mathrm{M}(-)$ & (Angry, Scheming) $>$ (Happy, Sad, Vacant) \\
\hline 11 & $\mathrm{~B}(\backslash /) \mathrm{M}(\cup)$ & Scheming $>$ (Happy, Sad, Vacant, Angry) \\
\hline 12 & $\mathrm{~B}(\backslash /) \mathrm{M}(\cap)$ & Angry $>* *$ Scheming $>^{*}$ (Happy, Sad, Vacan \\
\hline 13 & $\mathrm{~B}(/ \backslash) \mathrm{M}(-)$ & Sad $>\left(H^{*}\right.$ pp p \\
\hline 14 & $\mathrm{~B}(/ \backslash \mathrm{M}(-)$ & Sad $>$ (Happy , Ángry, Scheming, Vacânt) \\
\hline 15 & $\mathrm{~B}(/ \cup \mathrm{M}(\cup)$ & All Categories Equal \\
\hline 16 & $\mathrm{~B}(/ \cup \mathrm{M}(\cap)$ & Sad $>* *$ (Happy, A ngry, Scheming, Vacant) \\
\hline
\end{tabular}

\section{Facial Features and Meaningfulness}

Measures of the meaningfulness of each component feature were obtained by adding together the meaningfulness ratings for faces to which each component belonged. The score on each feature, averaged over the eight matched groups, is shown in Table 2.

One-way analyses of variance of scores on brow $[F(3,21)=33.8, p<.01]$ and mouth $[F(3,21)=24.7$, $\mathrm{p}<.011$ revealed significant differences in meaningfulness among the component features, and Tukey (a) tests produced the differences shown in Table 6.

Table 6 shows that medially downturned brows were most meaningful, followed by medially upturned brows, and finally horizontal brows; the upturned and downturned mouths were more meaningful than horizontal mouths. The only significant difference in meaningfulness for nose, eye height, and eye shape was on the latter $(t=2.51, p<.05)$, narrow eyes being more meaningful than wide eyes.

Since meaning was shown to be mainly a function of brow and mouth operating in combination, rather than in isolation, meaningfulness scores were found for the 16 brow/mouth combinations. These are shown in Table 4 . There were significant differences in meaningfulness among the combinations $[F(15,105)=7: 99, p<.01]$ and Tukey (a) comparisons, the results of which are diagrammed in Fig. 2, indicated where they lay.

It can be seen that the combinations of horizontal brows and horizontal mouth (Combinations 1-4) are least meaningful and that combinations involving two moving features (Combinations 11,12, and 16) are most meaningful. However, Combination 15, which has medially upturned brows and an upturned mouth, falls in the middle, along with the combinations having one moving feature. 


\section{Relation Between Meaning and Meaningfulness}

Since meaningfulness was defined as "ease of labeling," the meaningfulness of a face should be related to the number of adjectives rated as appropriate for the face; this was the case, since the correlation between meaningfulness and number of appropriate adjectives was significantly greater than zero $(r=.60, p<.01)$. An even stronger relationship was found between meaningfulness and the total number of meaning points assigned to a face $(r=.76)$, the difference between these two correlation coefficients being significant $(t=6.40$, $\mathrm{p}<.01)$.

\section{DISCUSSION}

The present results reinforce Ekman, Friesen, and Ellsworth's (1972) suggestion that different facial areas interact to determine expression: angry brows and a happy mouth interact to produce a highly meaningful scheming face, while sad brows and a happy mouth interact to produce a less meaningful face which does not consistently fall into any of the expression categories; neutral brows (high from the eyes) combine with a happy mouth to produce a fairly meaningful happy face, but neutral brows combined with a sad mouth do not result in a consistently identifiable expression. Ekman et al's other proposal, that each expression is not associated with one movement in each facial area, also receives some support: anger and sadness are associated with all mouths except one (the upturned mouth).

The second main conclusion from this study is that the particular expression on a face and its strength are mainly a function of its moving features (brow and mouth): when brow and mouth are both horizontal, faces are least meaningful and not readily identified; when the brows and, to a lesser extent, the mouth move from the horizontal, the face becomes more meaningful, its meaning being determined by the moving feature; when both brow and mouth move from the horizontal, the face is most meaningful and its meaning is a joint function of the moving features.

While this conclusion agrees with the findings of Harrison (1964), it goes a step further, by taking into account the strength of the relationship between a set of component features and their meaning. It is clear that there are variations in meaningfulness among faces identified with the same expression; for example, the

Table 6

Ordering of Each Feature Variation on Meaningfulness

\begin{tabular}{ll}
$\begin{array}{c}\text { Main } \\
\text { Feature }\end{array}$ & Ordering \\
\hline $\begin{array}{l}\text { Brow } \\
\text { Mouth }\end{array}$ & $\left.\mathrm{B}(1)<{ }^{* *} \mathrm{~B}(/)\right)<* *[\mathrm{~B}(-), \mathrm{B}(-)]$ \\
& {$[\mathrm{M}(\cap), \mathrm{M}(\cup)]<* *[\mathrm{M}(-), \mathrm{M}(-)]$} \\
\hline${ }^{*} p<.05$ & ${ }^{*} p<.01$
\end{tabular}

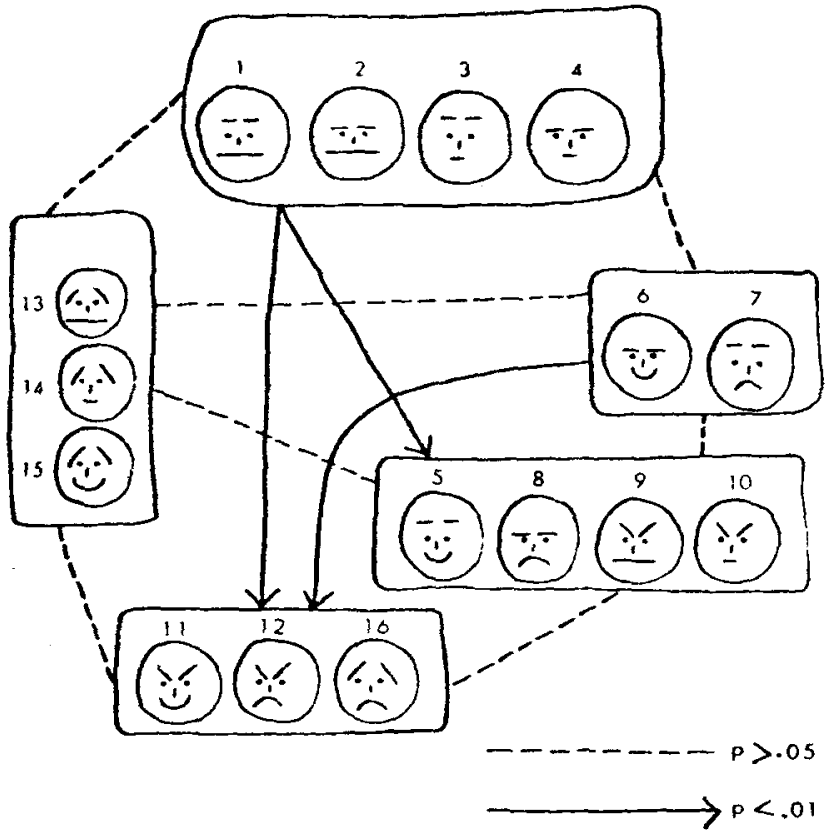

Fig. 2. Differences in meaningfulness among brow/mouth combinations (arrowheads indicate more meaningful combinations).

combination of medially downturned brows with a horizontal mouth and the combination of medially downturned brows with a downturned mouth are both identified as angry, although the latter are more meaningful. Some support for the validity of the direct ratings as a measure of meaningfulness is found in their high correlations with the number of appropriate adjectives given to a face (a standard measure of meaningfulness, Vanderplas \& Garvin, 1959) and with the number of meaning points assigned to a face (since this measure reflects the strength of association between the face and its appropriate adjectives). Thus, the present study clarifies the relationship between facial components and expression by showing how the moving features of brow and mouth interact to determine both meaning and meaningfulness.

It might be thought surprising that the eyes played such a small role in determining facial expression, since they have often been regarded as critical features. While eye shape was related to meaningfulness here, neither eye shape nor eye height contributed to meaning. Two suggestions can be offered to explain why eyes were not important in this study: Firstly, the alternatives chosen to represent the eyes may not have been crucial; there is some support for this possibility in Harrison's (1964) work, where he found the presence of eyelids in the drawing to be important. A second reason for the small role played by the eyes here may be that it is the eye area that is important, not just the eyes themselves. If that is true, such features as lines around the eyes or puckering of the skin between the eyes may have been mediated here by the moving brows, which were 
important determinants of expression.

Finally, mention should be made of the relevance of the present findings to various studies which have used schematic faces in information processing tasks (Friedman, Reed, \& Carterette, 1971; Kothurkar, 1965; Reed, 1972: Tversky. 1969). None of these studies used schematic faces varying in the angle of brow and mouth. Their generality is therefore limited, since the meaningfulness and meaning of the stimulus is an important determinant of performance in such tasks (Clark, 1965: Garner. 1970: Zusne, 1970).

\section{REFERENCES}

Bradshaw, J. L. The information conveyed by varying the dimensions of features in human outline faces. Perception \& Psychophysics, 1969, 6. 5-9.

Brunswik, E.. \& Reiter. L. Eindrucks-charactere schematiserter Gesichter. Zeitschrift für Psychologie, 1937, 142, 67-134.

Buzby: D. E. The interpretation of facial expressions. American Journal of Psychology, 1924, 35, 602-604.

Clark, H. J. Recognition memory for random shapes as a function of complexity, association value and delay. Journal of Experimental Psychology, 1965, 69, 590-595.

Davitz. J. R. The communication of emotional meaning. New York: McGraw-Hill, 1964.

Dunlap. K. The role of eye-muscles and mouth-muscles in the expression of the emotions. Genetic Psychology Monograph, 1927. 2. 199-233.

Ekman. P.. Friesen, W. V., \& Ellsworth, P. Emotion in the human face. New York: Pergamon Press, 1972.

Feleky. A. M. The expression of the emotions. Psychological Review, 1914, 21, 33-41.

Friedman. M. P.. Reed, S. K., \& Carterette, E. C. Feature saliency and recognition memory for schematic faces. Perception \& Psychophysics, 1971, 10, 47-50.

Frijda, N. H. The understanding of facial expression of emotion. Acta Psychologica, 1953, 9, 294-362.

Frois-Wittman, J. The judgement of facial expression. Journal of Experimental Psychology, 1930, 13, 113-151.

Garner, W. R. The stimulus in information processing. American Psychologist, 1970, 25, 350-358.

Hanawalt, N. G. The role of the upper and lower parts of the face as the basis for judging facial expressions: II. In posed expressions and "candid camera" pictures. Journal of General Psychology, 1944, 31, 23-36.
Harrison. R. P. Pictic analysis: Toward a vocabulary and syntax for the pictorial code: with research on facial communication. Unpublished doctoral thesis. Michigan State University. 1964.

Kanner. L. Judging emotions from tacial expressions. Psychology Monograph. 1931, 41(3, Whole No. 186).

Kothurkar. V. K. Effect of interpolated recall on recognition of schematic faces. Journal of Psychological Researches, 1965, 1. 11-14.

Landis. C. The interpretation of facial expression in emotion Journal of General Psychology. 1929, 2, 59-72.

Langfeld. H. S. The judgement of emotions from facial expressions. Journal of Abnormal \& Social Psychology. 1918. 13, $172-184$.

Munn. N. L. The effect of knowledge of the situation upon judgment of emotion from facial expressions. Journal of Abnormal \& Social Psychology. 1940, 35, 324-338.

Plutchik, R. The emotions: Facts, theories and a new model. New York: Random House, 1962.

Reed, S. K. Pattern recognition and categorization. Cognitive Psychology, 1972, 3. 382-407.

Rohracher, $H$. The psychological institute of the University of Vienna: Psychology of expressions. Acta Psychologica, 1951. 8, 201-233.

Ruckmick, C. A. A preliminary study of the emotions. Psychology Monograph, 1921, 30(Nos. 134-139), 30-35.

Samuels, M. R. Judgement of faces. Character \& Personality, $1939,8,18-27$.

Secord, P. F., \& Muthard, J. Personalities in faces: IV. A descriptive analysis of the perception of women's faces. and the identification of some physiognomic determinants. Journal of Psychology, 1955. 39, 269-278.

Tversky, A.. \& Krantz, D. H. Similarity of schematic faces: A test of interdimensional additivity. Perception \& Psychophysics, 1969, 5, 124-128.

Tversky, B. Pictorial and verbal encoding in a short-term memory task. Perception \& Psychophysics. 1969, 6. 225-233.

Vanderplas, J. M.. \& Garvin, E. A. The association value of random shapes. Journal of Experimental Psychology, 1959. 57, 147-154.

Winer, B. J. Statistical principles in experimental design. New York: McGraw-Hill. 1962.

Zusne, L. Visual perception of form. New York: Academic Press. 1970. Chap. 5.

(Received for publication November 20, 1972; revision received May 10, 1973.) 